\title{
The Experiment Study for Fatigue Strength of Bogie Frame of Beijing Subway Vehicle Under Overload Situation
}

\author{
Jishan $\mathrm{Li}^{1}$, Jinhai Wang ${ }^{2,3}, \mathrm{Xi} \mathrm{Li}^{4}$, Jianwei Yang ${ }^{*}, 2,3$ and Haitao Wang ${ }^{4}$ \\ ${ }^{1}$ Locomotive and Research Institute, China Academy of Railway Sciences, Beijing 100081, P.R. China \\ ${ }^{2}$ School of Machine-Electricity and Automobile Engineering, Beijing University of Civil Engineering and Architecture. \\ Beijing 100044, P.R. China \\ ${ }^{3}$ Beijing Engineering Research Center of Monitoring for Construction Safety, Beijing University of Civil Engineering \\ and Architecture, Beijing 100044, P.R. China \\ ${ }^{4}$ Subway Operation Technology Centre, Mass Transit Railway Operation Corporation LTD, Beijing 102208, P.R. China
}

\begin{abstract}
In this paper, a problem for safety of bogie frame of subway vehicle under overload situation has been discussed. Firstly, the structure of bogie frame and service condition are introduced to explain the reason caused fatigue failure. Then, the testing points are selected in terms of the structure of bogie frame, the characteristics of processing technique, load transfer path and the operation situation of subway vehicle. Based on them, the experiment for acquiring stress data during peak of service is done. After that, the process of fatigue analysis is presented with rainflow cycle counting method using the data above. From the Miner rule, nominal stress method and Goodman relation, the formula for fatigue strength assumed infinite life is obtained. Finally, the results of fatigue analysis according to the approach above is presented in the form of table. The research work provides guidance for maintaining the bogie frame.
\end{abstract}

Keywords: Bogie frame, fatigue strength, nominal stress method, subway vehicle.

\section{INTRODUCTION}

With the rapid increasing of passenger flow of subway vehicle, the duration of metro has become more important for assessment of service life. Especially, the safety of bogie frame is considerably influenced by the fatigue strength that is the ability of withstanding irregular loads under condition of fatigue crack development. According to statistics, the passenger flow of the peak during servicing is more than such 400 people that it cannot be estimated by design objective.

Oyan [1] studied fatigue strength of bogie frame of Taipei rapid transit systems using modified Goodman diagrams and finite element method. Dietz et al. [2] make use of multibody dynamic method and finite element method to assess the fatigue life prediction of bogie. Kiim et al. [3] evaluated the static structural safety and durability of two composite bogie frame models using a finite element analysis. Based on the Tsai-Wu failure criterion under ten different loading conditions, durability of bogie frame were researched using Goodman diagrams. Park et al. [4] applied finite element technical to calculate the fatigue strength of bogie frame based on UIC standard and minimize the weight of the bogie frame with a back-propagation artificial neural network. Beak et al. [5] predicted the fatigue life using nominal stress method based on rainflow cycle counting method and P-S-N curve for car bogie. Han et al. [6] evaluated experimentally fatigue strength for bogie frame of an urban maglev train and researched fatigue and damage. Moskvitin et al. [7] studied the effect of fatigue crack growth under overload situation.

Fig. (1) shows the structure of bogie frame of Beijing subway vehicle. Bogie frame consists of cross beam, air spring seat, side beam, lateral stop, longitudinal beam, rubber bushing seat, traction motor bracket and gearbox bracket. Its material properties is presented in Table $\mathbf{1 .}$

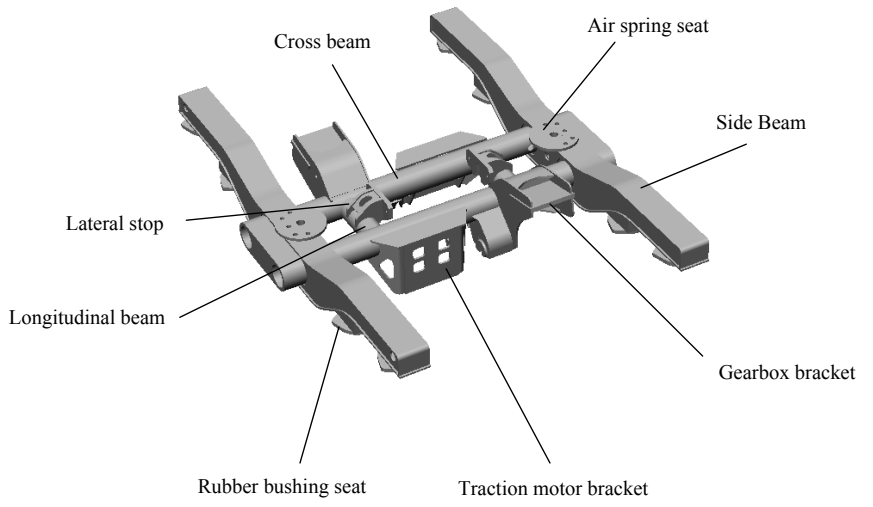

Fig. (1). The structure of bogie frame.

This paper aims to develop a fatigue analysis process based on experiment data. Section 2 describes the experiment method of stress acquisition of bogie frame 
during running in details to prepare for the follow-up work. Section 3 proposes the process for fatigue analysis using nominal stress method combined with rainflow counting method and Miner damage rule applied to calculate complex product that is bogie frame. Section 4 gives the result of analysis and concludes the advantages and disadvantages of the process given above.

Table 1. The properties of material Q345.

\begin{tabular}{|c|c|c|}
\hline Type & Value & Unit \\
\hline \hline Ultimate tensile strength & $470-360$ & $\mathrm{MPa}$ \\
\hline Yield strength & 345 & $\mathrm{MPa}$ \\
\hline Fatigue limit (Parent material) & 160 & $\mathrm{Mpa}$ \\
\hline Fatigue limit (Weld not griding) & 69 & $\mathrm{Mpa}$ \\
\hline Fatigue limit (Weld griding) & 108 & $\mathrm{Mpa}$ \\
\hline
\end{tabular}

\section{EXPERIMENT}

Due to Bogie frame always works under very complex and harsh situation that there are various direction load, its fatigue analysis becomes very difficult and complicated. For one hand, bogie frame absorbing static load which result from gravity of vehicle body, bogie and all kinds of parts installed on bogie frame. For another hand, bogie frame absorbing dynamic load which result from vibration of each parts due to track irregularity during running and inertia force during accelerating and braking. For this structure, the longitudinal forces exerted on the bogie frame through traction motor bracket and gearbox bracket.

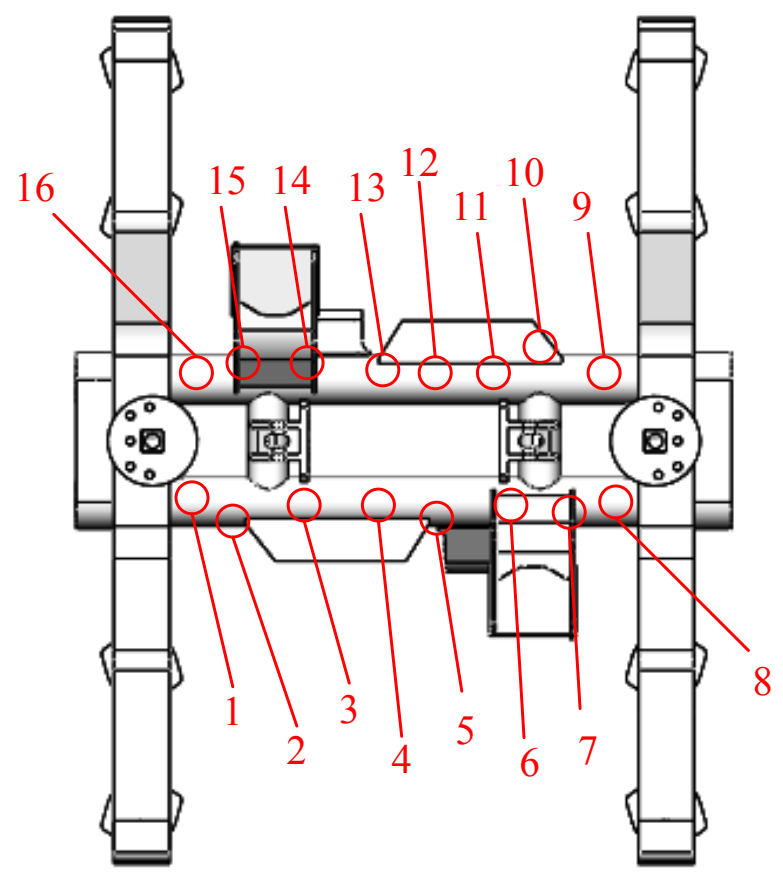

Top View

Fig. (2). The diagram of test point of bogie frame.
For anytime, it is unreasonable that bogie frame works under all loads given above is considered. In fact, bogie frame may work under only one or several of the loads at the same time. Therefore, various load situation should be taken into consideration when determining test points.

For acquiring the situation of bogie frame of subway vehicle, test points were determined according to the structure of bogie frame, the characteristics of processing technique, load transfer path and the operation situation of subway vehicle. Experiment was carried out total 68 points to acquire the stress histories as shown in Fig. (2).

For collecting time histories of stress to analyze the fatigue life, all data is collected using Agilent digital dynamic signal acquisition system which frequency of sampling is $500 \mathrm{~Hz}$ and resistance of strain gauge is $120 \Omega$. Because frequency of bogie frame is less than $50 \mathrm{~Hz}$ generally, filter is unnecessary for collected data.

To obtain the real situation of stress of bogie frame of subway vehicle during running, the peak period in morning and afternoon is selected as test time. Fig. (3) shows the stress history of test point No. 13 and No. 20.

From the result of experiment, all of stress on histories is much less than the yield strength. From the mechanics of materials, it won't be destroyed and it has infinite life. However, the fact is not like this according to maintenance record which includes damage or failure data of bogie frame. Therefore, a fatigue analysis which is a method to assess the safety of product which works under yield strength need to be performed.

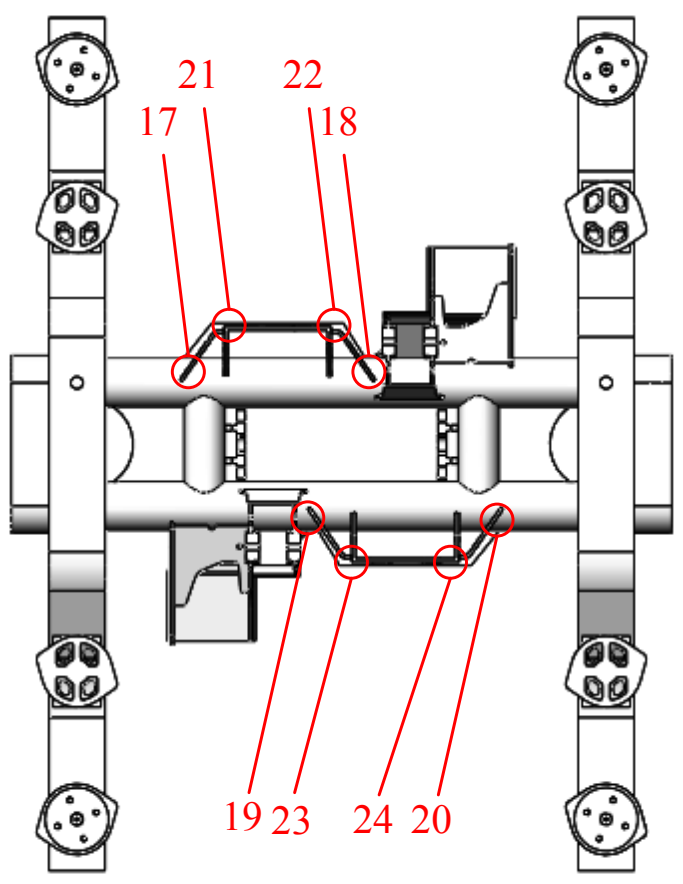



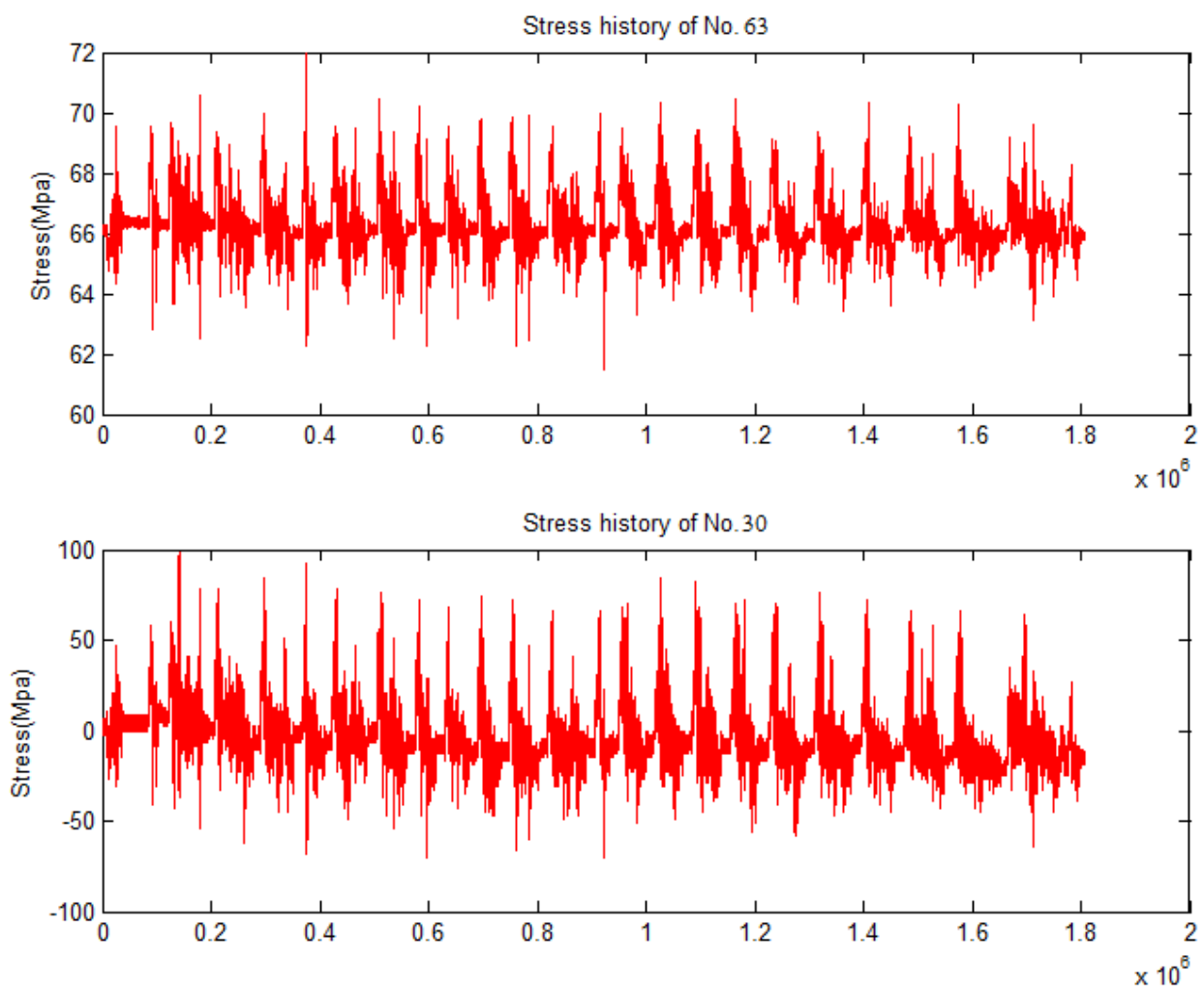

Fig. (3). The stress histories of test point No. 13 and No. 20.

\section{FATIGUE ANALYSIS}

Generally, there are three methods for predicting the fatigue life: nominal stress method, local strain method and fracture mechanics method. In this paper, nominal stress method is used on fatigue analysis of bogie frame due to it is extensive, simple and convenient. The nominal stress method is given in Fig. (4).

\subsection{Rainflow Cycle Counting Method}

Counting method which influences the precision of fatigue analysis is a key process for predicting life of product. Rainflow counting method which is one of the most famous two-parameters counting methods is used in the work due to its application widely.

The whole scheme of rainflow cycle counting method is given simply as follow:

(1) Rearrange stress history in order to define a start point using a bigger one between peaks and valleys depending on absolute value of them.

(2) Assume that a raindrop flows down from the first peak or valley. And it does not stop until a higher peak or lower valley.

(3) Record the stress cycle that is closed obtained above.

(4) Repeat form (1) to (4) until no more cycles are closed.

Based on the process above, a regular stress history which consist of different cycles is acquired. And then, the fatigue strength analysis which applies nominal stress method can be performed using the stress history. The result of rainflow cycle counting for No.13 is shown in Fig. (5).

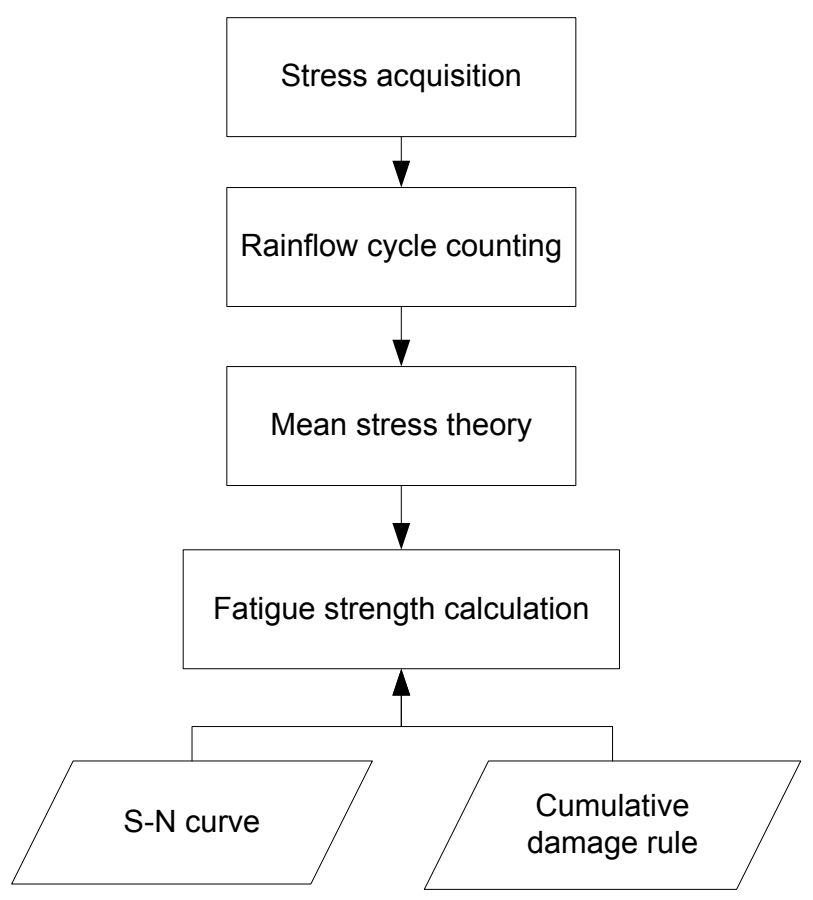

Fig. (4). The process of fatigue strength analysis.

\subsection{Fatigue Strength Calculation}

In nominal stress method, S-N curve which is a relationship for special material between stress level and life 


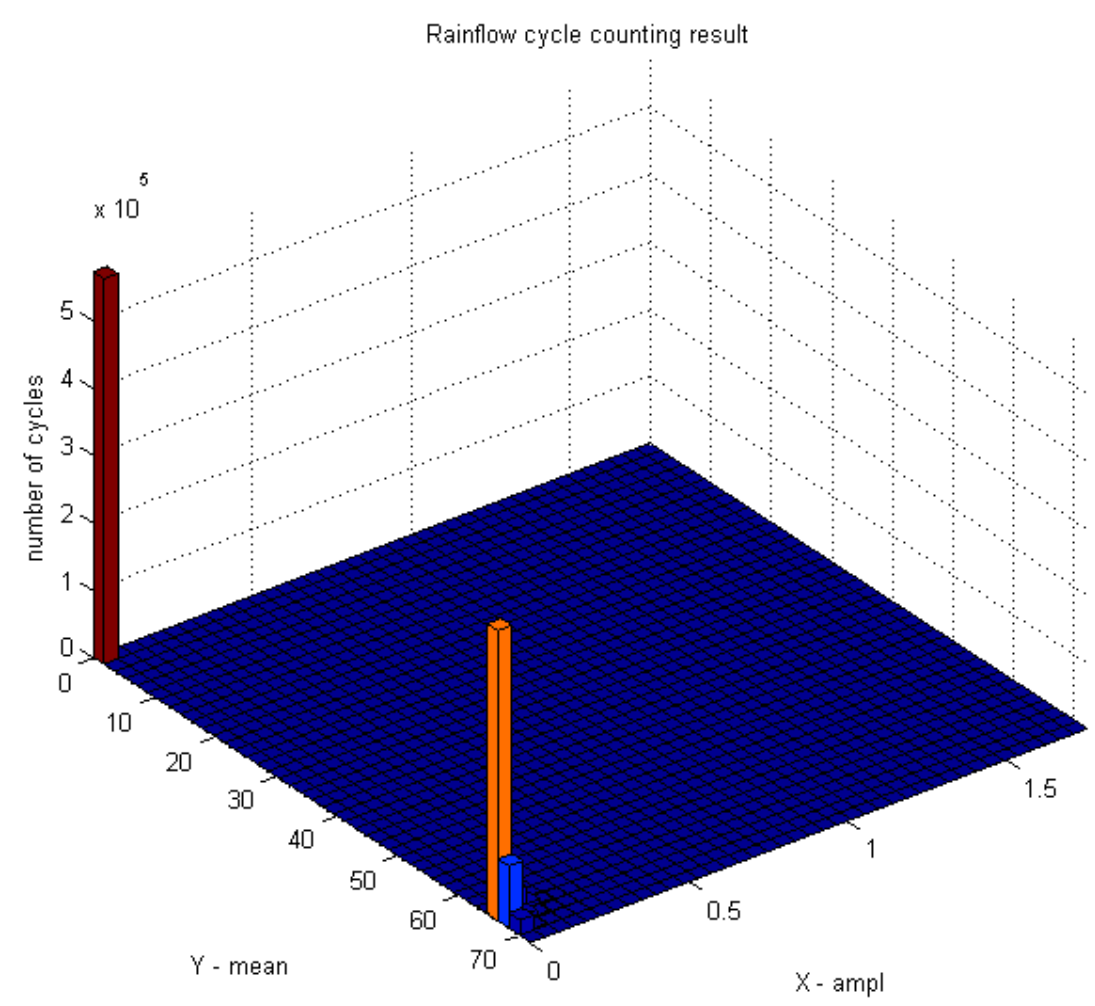

(a) The matrix of rainflow cycle counting result

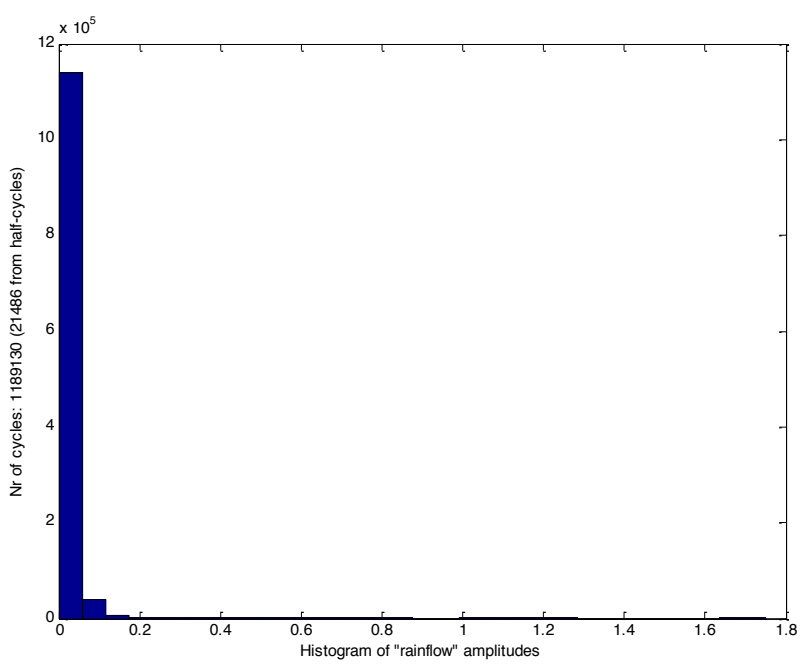

(b) The amplitudes of rainflow cycle counting result

Fig. (5). The result of rainflow cycle counting for No.13.

of standard specimen is a key tool in fatigue analysis. This relationship can be addressed as follow,

$N S^{m}=C$

where $m$ and $C$ are constant of material, $\mathrm{S}$ is stress, $\mathrm{N}$ is cycle number when specimens fail. In this study, $m$ is 3.5 for welding structure and 5 for parent material.

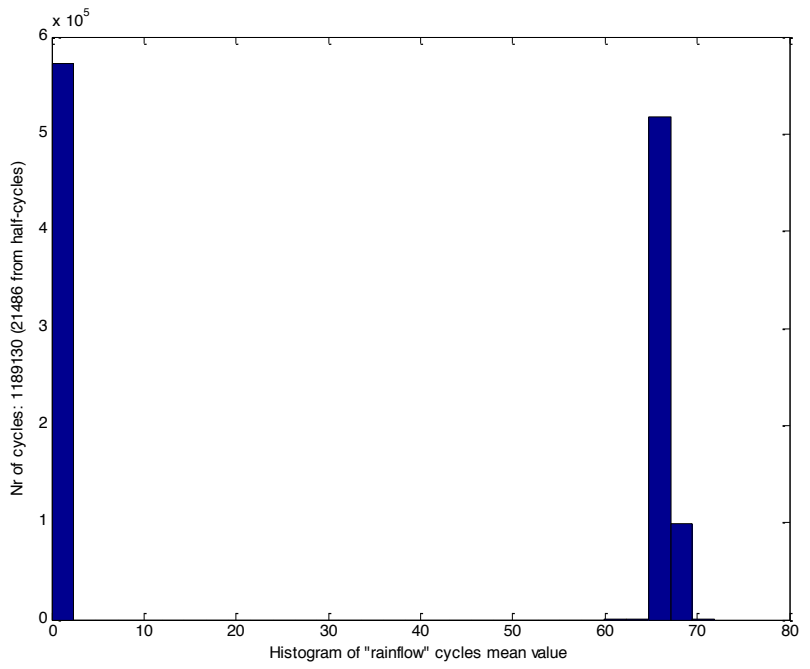

(c) The mean value of rainflow cycle counting result

For most of material, S-N curve is obtained under symmetric stress cycle whose stress ratio equal to -1 and there is lack of S-N curve under other stress ratio. To crack this hard nut, the mean stress theory transferring S-N curve under any stress ratio to symmetric stress cycle. The most famous relation in the mean stress theory is linear alternating 
Table 2. The result of fatigue strength analysis for bogie frame.

\begin{tabular}{|c|c|c|c|}
\hline Number & Location & The fatigue strength of $\boldsymbol{L}_{\text {infinite }}=\mathbf{3 0 0} \mathbf{~ k m ~ ( M p a )}$ & The fatigue strength of $\boldsymbol{L}_{\text {infinite }}=\mathbf{3 6 0} \mathbf{~ k m}$ (Mpa) \\
\hline \hline 3 & Traction motor bracket & 70.3 & 72.8 \\
\hline 5 & Traction motor bracket & 67.8 & 71.5 \\
\hline 13 & Traction motor bracket & 69.6 & 72.3 \\
\hline 17 & Traction motor bracket & 69.1 & 72.8 \\
\hline 21 & Traction motor suspender & 123.9 & 128.5 \\
\hline 15 & Gearbox bracket & 71.0 & 72.9 \\
\hline
\end{tabular}

relationship as called Goodman relation. The mathematical description can be presented as,

$$
\sigma_{-1 N}=\frac{\sigma_{a} \sigma_{b}}{\sigma_{b}-\sigma_{m}}
$$

where $\sigma_{-1 N}$ is equivalent stress, $\sigma_{a}$ is the amplitude of stress, $\sigma_{m}$ is the mean value of stress, $\sigma_{b}$ is tensile strength of the material.

From (1), a expression of material under fatigue limit is given by

$N_{-1} \sigma_{-1}^{m}=C$

where $N_{-1}$ is cycle number for fatigue limit, $\sigma_{-1}$ is fatigue limit. And also, a relation for the general case of fatigue failure under symmetric stress cycle can be written,

$N_{-1} \sigma_{-1}^{m}=N \sigma_{-1 N}^{m}=C$

where $N$ is cycle number for fatigue strength.

Cumulative damage rule is a theory to estimate the fatigue strength of structure and identify the fatigue load condition. For infinite life design for very high mean stress and varying stress under different stress ratio, the Miner rule which is also called linear cumulative damage hypothesis is selected. The Miner rule is presented as follow. Failure is expected to occur if

$D=\frac{n_{1}}{N_{1}}+\frac{n_{2}}{N_{2}}+\frac{n_{3}}{N_{3}} \cdots=\sum_{i=1}^{w} \frac{n_{i}}{N_{i}}$

where $D$ is cumulative damage, $n_{i}$ is the real cycle number of the $i$ th stress level, $N_{i}$ is the maximum cycle number of the $i$ th stress level. by

Substituting (4) to (5), the real damage can be obtained

$D_{\text {real }}=\sum_{i=1}^{w} \frac{n_{i} \sigma_{-1 N i}{ }^{m}}{C}$

where $D_{\text {real }}$ is the damage of test data, $\sigma_{-1 N i}$ is the equivalent stress for $i$ th stress level, $n_{i}$ is the real cycle number for $i$ th stress level. On the same principle,

$D_{\text {infinte }}=\frac{n_{\text {infinite }} \sigma_{\text {infinite }}{ }^{m}}{C}$

where $D_{\text {infinite }}$ is the damage of transforming to infinite life, $\sigma_{\text {infinite }}$ is the fatigue strength, $n_{\text {infinite }}$ is the cycle number for infinite life. Here $n_{\text {infinite }}$ is $2 \times 10^{6}$ for welding structure and $10^{7}$ for base material.

For subway vehicle, a appropriate service life is selected as a standard to define a infinite life. In this paper, $360 \mathrm{~km}$ is defined as the infinite life. Considering the same damage per kilometer, a equal damage expression is represented as follow,

$\frac{D_{\text {infinite }}}{L_{\text {infinite }}}=\frac{D_{\text {real }}}{L_{\text {real }}}$

where $L_{\text {infinite }}$ is the service life of transforming to infinite life, $D_{\text {real }}$ is the damage under real situation, $L_{\text {real }}$ is the service distance under real situation. Here $L_{\text {real }}$ is $330 \mathrm{~km}$.

From (6), (7) and (8), the stress of transformed to infinite life can be obtained as,

$\sigma_{\text {infinite }}=\left[\frac{L_{\text {infinite }}}{L_{\text {real }} n_{\text {infinite }}} \sum_{i=1}^{w} n_{i}\left(\sigma_{-1 N i}\right)^{m}\right]^{1 / m}$

\section{CONCLUSION}

Based on the process given above, the fatigue strength of transformed to infinite life is calculated for each testing point of bogie frame. Table 2 shows the fatigue strength for some dangerous points in details.

The experiment and fatigue analysis results indicate that the weak location is around traction motor bracket and suspender and gearbox bracket. And the fatigue strength of the most dangerous point aside on traction motor suspender is larger than fatigue limit of base material. It cannot satisfy the requirements of $360 \mathrm{~km}$ service life under overload situation. And also, the status of this location should be taken more seriously during service period.

\section{CONFLICT OF INTEREST}

The authors confirm that this article content has no conflict of interest.

\section{ACKNOWLEDGEMENTS}

This paper was supported by the national natural science fund project (51175028), Beijing outstanding talent training projects (2010D005017000007) and the International Science \& Technology Cooperation Program of China (2014DFR70280). 


\section{REFERENCES}

[1] C. Oyan, "Structural strength analysis of the bogie frame in Taipei rapid transit systems: Proceedings of the Institution of Mechanical Engineers," Part F: Journal of Rail and Rapid Transit, vol. 212, pp. 253-262, 1998.

[2] S. Dietz, H. Hetter, and D. Sachau, "Fatigue life prediction of a railway bogie under dynamic loads through simulation", Vehicle System Dynamics, vol. 29, pp. 385-402, 1998

[3] J.S. Kim, K.B. Shin, H.J. Yoon, and W.G. Lee, "Durability evaluation of a composite bogie frame with bow-shaped side beams", Journal of Mechanical Science and Technology, vol. 26, pp. 531-536, 2012.
[4] B.H. Park, N.P. Kim, J.S. Kim, and K.Y. Lee, "Optimum design of tilting bogie frame in consideration of fatigue strength and weight", Vehicle System Dynamics, vol. 44, pp. 887-901, 2006.

[5] S.H. Baek, S.S. Cho, and W.S. Joo, "Fatigue life prediction based on the rainflow cycle counting method for the end beam of a freight car bogie", International Journal of Automotive Technology, vol. 9, pp. 95-101, 2008.

[6] J.W. Han, J.D. Kim, and S.Y. Song, "Fatigue strength evaluation of a bogie frame for urban maglev train with fatigue test on full-scale test rig", Engineering Failure Analysis, vol. 31, pp. 412-420, 2013.

[7] G.V. Moskvitin, and S.G. Lebedinskii, "Effect of overloads on fatigue crack growth regularity within steel molded pieces of freight cars", Journal of Machinery Manufacture and Reliability, vol. 42, pp. 439-444, 2013.

Received: January 8, 2015

Revised: January 15, 2015

Accepted: January 16, 2015

(C) Li et al.; Licensee Bentham Open.

This is an open access article licensed under the terms of the Creative Commons Attribution Non-Commercial License (http://creativecommons.org/licenses/by-nc/3.0/) which permits unrestricted, non-commercial use, distribution and reproduction in any medium, provided the work is properly cited. 